\title{
$\$$ Research Square

\section{Metagenomic Insights Into Co-Proliferation of Vibrio Spp. and Dinoflagellates Prorocentrum During A Spring Algal Bloom in the Coastal East China Sea Near Xiamen}

\section{DaeHyun Daniel Kim}

Korea Advanced Institute of Science and Technology

\section{Lingling Wan}

Institute of Hydrobiology Chinese Academy of Sciences

\section{Xiuyun Cao}

Institute of Hydrobiology Chinese Academy of Sciences

Daniela Klisarova

Medical University of Varna

Dimitar Gerdzhikov

Institute of Fish Resources

Yiyong Zhou

Institute of Hydrobiology Chinese Academy of Sciences

Chunlei Song

Institute of Hydrobiology Chinese Academy of Sciences

Sukhwan Yoon ( $\nabla$ syoon80@kaist.ac.kr)

Korea Advanced Institute of Science and Technology https://orcid.org/0000-0002-9933-7054

\section{Research}

Keywords: algal, vibrio, prokaryotic, coastal, microbiomes, prorocentrum, proliferation

Posted Date: June 30th, 2021

DOl: https://doi.org/10.21203/rs.3.rs-651878/v1

License: (c) (i) This work is licensed under a Creative Commons Attribution 4.0 International License. Read Full License 


\section{Abstract}

\section{Background}

Coastal harmful algal blooms (HAB), commonly termed 'Red tides', have severe undesirable consequences to the marine ecosystems and local fishery and tourism industries. Increase in nitrogen and/or phosphate loading is often attributed as the major culprits of increasing frequency and intensity of the coastal HAB; however, fundamental understanding is lacking as to the causes and mechanism of bloom formation despite decades of intensive investigation.

\section{Results}

In this study, we interrogated the prokaryotic microbiomes of surface water samples collected at two neighboring segments of East China Sea that contrast greatly in terms of the intensity and frequency of Prorocentrum-dominated HAB. Mantel tests identified significant correlations between the structural and functional composition of the microbiomes and the physicochemical state and the algal biomass density of the surface seawater, implying the possibility that prokaryotic microbiota may play key roles in coastal HAB. A conspicuous feature of the microbiomes at the sites characterized with high trophic state index and eukaryotic algal cell counts was disproportionate proliferation of Vibrio spp., and their complete domination of the functional genes attributable to the dissimilatory nitrate reduction to ammonia (DNRA) pathway significantly enriched at these sites. The genes attributed to phosphorus uptake function were also significantly enriched at these sites, presumably due to the $\mathrm{P}_{\mathrm{i}}$-deficiency induced by algal growth; however, the profiles of the phosphorus mineralization genes lacked consistency, barring any conclusive evidence with regard to contribution of prokaryotic microbiota to phosphorous bioavailability. The results of the co-occurrence network analysis performed with the core prokaryotic microbiome also supported that the observed proliferation of Vibrio and HAB may be causally associated.

\section{Conclusions}

The findings of this study suggest a previously unidentified association between Vibrio proliferation and the Prorocentrum-dominated HAB in the subtropical East China Sea, and opens a discussion regarding an unlikely, but still possible, involvement of Vibrio-mediated DNRA in Vibrio-Prorocentrum symbiosis. Further substantiation of this interaction with culture-based experiments may prove crucial for understanding of the dynamics of explosive local algal growth during HAB events endemic to the region.

\section{Background}

Today, many coastal regions across the globe suffer from harmful algal blooms (HAB), more widely known as the layman's term 'red tides'[1]. The East China Sea off the southeast coast of China has been one of the regions most severely affected by HAB since the 1980s [2]. Since the turn of millennium, the major culprits of HAB in the East China Sea have shifted to the dinoflagellates Prorocentrum spp., a group of fast-growing phototrophic algae widespread in coastal waters across the globe [3]. The species 
prevalent in $\mathrm{HAB}$ in East China Sea, which had been named $P$. donghaiense, is neither morphologically nor genotypically clearly distinguishable from other Prorocentrum species with worldwide distribution, e.g., $P$. dentatum and $P$. obtusidens $[4,5]$. Although toxin production by this particular species has not been reported, the possibility cannot be totally ruled out, as several Prorocentrum species have been observed to produce okadaic acid, dinophysistoxin-1, and prorocentrolide [6, 7]. Even apart from toxin production, intense Prorocentrum blooms cause substantial detrimental impacts to the local marine and estuarine ecosystems by means of oxygen depletion, alteration of $\mathrm{pH}$, and/or light attenuation, which are typical for high-biomass algal blooms $[1,8,9]$. Such ecological damage, as well as aesthetic deterioration due to coloration and putrefaction accompanied with the blooms, have caused immense damage to the local tourism, fishing, and aquaculture industries [10].

The annually repetitive nature of the Prorocentrum algal bloom in the East China Sea, as well as explosive growths of $P$. donghaiense observed during progressions of the algal blooms endemic to the region, suggests that in situ growth is more important than vertical and/or horizontal migration in understanding the mechanisms of bloom dynamics in the region $[11,12]$. As $P$. donghaiense is primarily a photoautotrophic organism with carbon needs mostly fulfilled from uptake of inorganic carbon, the environmental factors regarded to be crucial to its overgrowth during the bloom events are presumably availability of nitrogen and phosphorous, as suggested by previous laboratory observations $[1,13,14]$. Although several published data collected from the East China Sea suggest potential correlations between nitrogen and phosphorous availability and $P$. donghaiense blooms, conclusive experimental evidences are still lacking, and it is yet unclear whether or which specific forms of nitrogen and phosphorous support rapid growth of $P$. donghaiense $[15,16]$. As such, the decades-long question as to whether or how relief of nitrogen and/or phosphorous limitation initiates $P$. donghaiense bloom remains unanswered.

In this study, we approached this same old question from a different perspective, exploring the possibility that the sea surface microbiome may play a key role in formation and progression of Prorocentrum blooms. Diverse bacterial and archaeal constituents of the sea surface microbiota are involved with cycling of nitrogen and phosphorous [17]. In the euphotic zone, generally characterized by supple sunlight and oxygen availability, photosynthetic cyanobacteria fix atmospheric nitrogen to ammonium and organic nitrogen, and diverse bacteria and archaea catalyze aerobic mineralization of organic $\mathrm{N}$ and oxidation of $\mathrm{NH}_{3}$ and $\mathrm{NO}_{2}{ }^{-}$[18-20]. Typically, $\mathrm{NO}_{3}{ }^{-}$is often the most abundant form of nitrogen at the sea surface due to its oxidizing condition [21,22]. The microbial reactions perceived as predominantly anaerobic, e.g., denitrification, anaerobic ammonia oxidation (anammox), and dissimilatory nitrate/nitrite reduction to ammonium (DNRA), may also occur during periodic hypoxia, e.g., nocturnal anoxic spells during high-biomass algal blooms and periods of massive biomass decay following demise of algal blooms $[23,24]$. Such microbial mediated nitrogen transformation reactions may affect nitrogen supply to phytoplankton, as they may alter the overall nitrogen availability, as well as nitrogen speciation. As nitrogen is often regarded as the limiting nutrient for algal growth during rapid blooms and previous laboratory experiments have shown that certain nitrogen species are favored by Prorocentrum spp. over 
others, investigations into these microbially mediated nitrogen-transformations may help improve understanding of the bloom dynamics in the East China Sea $[3,13,25]$.

Less predictable is the influence of microbiota on HAB via alteration of the marine phosphorus cycle, given the patchy ecophysiological understanding of marine microbial phosphorous metabolism. Previous metagenomic analyses have revealed abundance and omnipresence of diverse $p h o A-$, phoD-, and phoXtype alkaline phosphatases (AP) and C-P lyases and hydrolases in seawater microbiomes, which have been known to be involved with disintegration of inorganic phosphorus $\left(\mathrm{P}_{\mathrm{i}}\right)$ from phosphoesters and phosphonates [26-28]. Expressions of these organic phosphorus metabolizing enzymes are generally perceived to be under Pho regulon control, such that they are expressed only under $\mathrm{P}_{\mathrm{i}}$-deficiency; however, $\mathrm{P}_{\mathrm{i}}$-insensitive expression and activity of alkaline phosphatases and C-P hydrolases have been experimentally demonstrated in both in situ and laboratory experiments [29, 30]. Thus, bacterial mineralization of organic phosphorus may enrich the inorganic phosphorus pool in situ and increase phosphorous bioavailability to phytoplanktons, contributing to formation of $\operatorname{HAB}[27,31,32]$. Marine eukaryotic phytoplankton, including Prorocentrum spp., also synthesize active AP [32-34]; however, a recent field study conducted in the East China Sea during a late-spring $P$. donghaiense bloom showed that the bacterial fraction accounted for the majority of AP activity and that the contribution of eukaryotic algae was minimal [35].

Here, a comparative survey of the sea surface microbiomes was performed at two neighboring coastal seas off the coastline of Fujian Province in South China. The sea surrounding Pingtan Island, hereafter referred to as Pingtan Sea, has been regularly and frequently affected by $P$. donghaiense blooms. In contrast, Xiamen Bay $200 \mathrm{~km}$ to the southwest has stayed mostly free of Prorocentrum spp., although occasional occurrences of moderate diatom and dinoflagellate blooms have been reported [36]. During a typical spring dinoflagellate bloom event in the Pingtan Sea in 2019, surface seawater samples were collected from five locations in Pingtan Sea and three locations in Xiamen Bay, varying in the intensity of $\mathrm{HAB}$ at the time of sampling, and the physicochemical properties of the seawater and population densities and compositions of the eukaryotic algae were analyzed. The microbiomes of these seawater samples were then analyzed with shotgun metagenome sequencing. The compositional and functional features of the microbiomes were analyzed, with particular emphasis on those relating to nitrogen and phosphorous metabolism and statistically associated with the severity of HAB in the region. The findings from the comparative metagenomics analysis warrant further investigation into interactions between key microbial groups, e.g., Vibrio spp., and eukaryotic algae, for a more complete understanding of HAB dynamics in coastal seas.

\section{Results And Discussion}

\section{Characterization of the sampling sites}

Notable differences were observed between the physicochemical characteristics of the surface water samples collected from the Pingtan Sea (PIN1-PIN5) and the Xiamen Bay (XIA1-XIA3) (Fig. S1, Table S1). 
The surface water temperature was higher at the Xiamen Bay sites by approximately $3^{\circ} \mathrm{C}$ at the time of sampling, and the $\mathrm{pH}$ and salinity were slightly but significantly higher $(p<0.05)$ at the Pingtan Sea sites. The dissolved oxygen (DO) concentration of the surface water ranged between 4.7 and $6.9 \mathrm{mg} / \mathrm{L}$, but no significant difference was found between the two regions $(p>0.05)$. The measured oxidation reduction potential (ORP) values were $43.9 \pm 2.5 \mathrm{mV}$ and $22.1 \pm 6.5 \mathrm{mV}$ at the Pingtan Sea and the Xiamen Bay sites, respectively (Fig. S1). Overall, Xiamen Bay was more nutrient-rich than the Pingtan Sea. The dissolved inorganic nitrogen (DIN) concentration was significantly higher $(p<0.05)$ in the Xiamen Bay samples $(1.5 \pm 0.3 \mathrm{mg}-\mathrm{N} / \mathrm{L})$ than in the Pingtan Sea samples $(0.76 \pm 0.2 \mathrm{mg}-\mathrm{N} / \mathrm{L})$. The $\mathrm{NO}_{3}{ }^{-}$and $\mathrm{NO}_{2}{ }^{-}$concentrations were both significantly higher $(p<0.05)$ in Xiamen Bay with $1.1 \pm 0.2 \mathrm{mg} \mathrm{NO}_{3}-\mathrm{N} / \mathrm{L}$ and $0.070 \pm 0.020 \mathrm{mg}$ $\mathrm{NO}_{2}{ }^{-}-\mathrm{N} / \mathrm{L}$, as compared to $0.53 \pm 0.08 \mathrm{mg}-\mathrm{NO}_{3}{ }^{-}-\mathrm{N} / \mathrm{L}$ and $0.010 \pm 0.001 \mathrm{mg} \mathrm{NO}_{2}{ }^{-}-\mathrm{N} / \mathrm{L}$ measured in Pingtan Sea. $\mathrm{NH}_{4}{ }^{+}$concentrations were not significantly different $(p>0.05)$ between Xiamen Bay $(0.31 \pm 0.11 \mathrm{mg}$ $\left.\mathrm{NH}_{4}{ }^{+}-\mathrm{N} / \mathrm{L}\right)$ and Pingtan Sea $\left(0.23 \pm 0.10 \mathrm{mg} \mathrm{NH}_{4}{ }^{+} \mathrm{N} / \mathrm{L}\right)$ (Fig S1). The concentrations of soluble reactive phosphorus (SRP), dissolved total phosphorus (DTP), and total phosphorus (TP) were all significantly higher in Xiamen Bay than Pingtan Sea (Fig. S1). Depletion of SRP was particularly notable in the surface seawater of the Pingtan Sea, as the SRP concentrations measured at the Pingtan Sea sites were $26 \pm 18 \%$ of the concentrations measured at the Xiamen Bay sites. The DTN-to-DTP ratio was significantly higher $(p<0.05)$ in Pingtan Sea.

According to the criterion based on the Carlson's Trophic Indices (TSI), three of the five sampling locations in Pingtan Sea (PIN1, PIN4, and PIN5) and two of three in Xiamen Bay (XIA1 and XIA2) were classified as eutrophic (TSI>50). The total eukaryotic algal cell count was the highest at PIN4 $\left(1.2 \times 10^{6}\right.$ cells/L), and the algal cells morphologically identified as Prorocentrum spp. accounted for $91.0 \%$ of the total algal population (Table S2). The only other site with a substantial Prorocentrum spp. population was PIN5, where $3.6 \times 10^{5}$ cells/L, out of the total algal population of $5.2 \times 10^{5}$ cells/L, were identified as Prorocentrum spp. The total $16 \mathrm{~S}$ rRNA gene copy numbers, as an indicator of prokaryotic population, ranged between $9.9 \pm 1.3 \times 10^{7}$ and $4.2 \pm 0.2 \times 10^{8}$ copies/L in Pingtan Sea and between $9.1 \pm 0.9 \times 10^{7}$ and $2.9 \pm 0.9 \times 10^{8}$ copies/L in Xiamen Bay (Fig $1 \mathrm{~b}$ and Table S2).

\section{Analysis of prokaryotic community and core microbiome designation}

Analysis of the prokaryotic community structures of PIN1-5 and XIA1-3 identified Proteobacteria as the dominant phylum, with its relative abundance ranging from $76.4 \%$ to $88.2 \%$ (Fig. 2a).

Alphaproteobacteria and Gammaproteobacteria constituted $18.0-34.6 \%$ and $41.5-70.0 \%$ of the prokaryotic communities, respectively. Bacteroidia were also abundant, constituting $6.3-17.0 \%$ of the total prokaryotic community. Although archaeal OTUs affiliated to Thermoplasmata and Nitrososphaeria were found in the metagenomes, the cumulative relative abundance of the archaeal OTUs was below $1.5 \%$ in any of the samples analyzed. The beta diversity analysis of the sea surface microbiomes clearly set the Pingtan sites apart from the Xiamen sites (Fig. 2c-e). The non-metric multidimension scaling (NMDS) plots constructed via taxonomic grouping of 16S rRNA gene sequences and functional assignments of translated enzyme sequences to KEGG Orthology (KO) groups and CAZymes groups invariably separated 
PIN1-5 from XIA1-3 (Fig. 2c-e), suggesting disparities between the microbiomes of these two regions, in terms of both taxonomic and functional make-ups.

The pairwise Mantel tests identified significant correlations between the taxonomic and functional compositions of the microbiomes and the states of the surface seawater at the Pingtan and Xiamen sites (Fig. 2b). Significant correlation was observed between algal biomass and 16S rRNA-based community composition $\left(r_{\mathrm{m}}=0.39, p=0.04\right)$. Algal biomass was also significantly correlated with the functional profiles of the microbiomes $\left(r_{\mathrm{m}}=0.55, p=0.03\right.$ and $r_{\mathrm{m}}=0.55, p=0.03$ for correlations with KO-based and CAZyme-based functional profiles, respectively). A stronger statistically significant correlation was observed between the physicochemical states of the seawater and the prokaryotic community compositions $\left(r_{\mathrm{m}}=0.61, p=0.002\right)$ and the KO-based and CAZyme-based functional profiles $\left(r_{\mathrm{m}}=0.57\right.$, $p=0.001$ and $r_{\mathrm{m}}=0.71, p=0.002$, respectively) of the microbiomes. The physicochemical states were not significantly correlated with the algal biomass $\left(r_{\mathrm{m}}=0.35, p=0.093\right)$, suggesting that a snapshot of the physicochemical state of seawater is not sufficient as an indicator for HAB. Possibly, the significant correlation between the microbiome composition and the algal biomass may imply that the history of the recent biogeochemical events, missing in a snapshot characterization of physicochemical properties, is ingrained in the taxonomic and functional compositions of the microbiome [37]. Another possible scenario that can be inferred from the Mantel test results is the microbiota shaped by environmental pressure playing a direct role in algal bloom development, in a sense analogous to the key principle underlying diet-microbiome-host interactions in human and animal guts [38].

The OTUs identified in the samples were assigned to 379 bacterial and 5 archaeal taxa (according to genus-level classification), and 47 of these taxa, shared by all 8 metagenomes, were further considered as the members of the core microbiome (Table S3). The core microbiome consisted of 46 bacterial taxa and one archaeal taxon, most of which are uncultured and understudied. The members of the core microbiome constituted vast majority of the total prokaryotic community in each of the analyzed samples, such that their cumulative relative abundance ranged between 70.4 and $76.9 \%$ at the Pingtan Sea sites and between 62.6 and $73.6 \%$ at the Xiamen Bay sites (Table S3). The core microbiome taxa with $>1 \%$ relative abundance at all sites included the SAR11 clade, Pseudoalteromonas, Vibrio, Candidatus Actinomarina, the NS5 marine group, and an unidentified genus of Rhodobacteraceae. The high abundance of Vibrio spp. at PIN1, PIN4, PIN5, and XIA1 was especially notable. Vibrio spp. constituted $15.2 \%, 32.7 \%, 9.9 \%$, and $19.3 \%$ of the prokaryotic populations at the respective sites, all of which were categorized as eutrophic according to their TSI values $(>50)$. The relative abundance of the Vibrio was $<4.5 \%$ at the other four sites, where, with sole exception of XIA2, the TSI values indicated mesotrophic conditions. Another core microbiome taxon affiliated to the Vibrionaceae family (unassignable to any distinct genus) was found at PIN2 and PIN3 sites with $>10 \%$ relative abundance; however, its low abundance in PIN4 (1.3\%) suggests relevance of this taxon to eutrophication or algal bloom unlikely.

\section{Metagenomic analysis of nitrogen and phosphorus metabolism}


The metagenomic profiles of nitrogen metabolism-related genes in the microbiomes suggest possible involvement of the prokaryotic microbiome in altering the availability of labile nitrogen to Prorocentrumdominated algal populations (Fig. 3 and Table S4). Apart from the genes involved with urea uptake and mineralization (ure $A B C$ and $u r t A B C D E$ ), all of the most abundant nitrogen functional genes were relevant to dissimilatory and assimilatory $\mathrm{NO}_{3}{ }^{-}$-to- $\mathrm{NO}_{2}{ }^{-}$reduction (napAB and nasA) and dissimilatory nitrite reduction to ammonium (DNRA; $n r f A$ and $n i r B$ ). The genes encoding for the periplasmic nitrate reductase, napAB, had substantially higher relative abundance at the Pingtan Sea sites (10.2-39.8 RPKM for napA and 6.0-27.3 RPKM for napB) than in the Xiamen Bay sites (6.9-17.1 RPKM for napA and 8.0-14.2 RPKM for $n a p B)$, although the differences were not statistically significant $(p>0.05)$. The $n i r B$ and $n r f A$ genes, encoding the catalytic subunits of the two distinct forms of nitrite reductases central to the DNRA pathway, showed high relative abundance at the Pingtan Sea and Xiamen Bay sites [39]. The relative abundance of nirB ranged between 26.6 and 87.5 RPKM in the Pingtan Sea metagenomes, and 17.5 and 50.4 RPKM in the Xiamen Bay metagenomes. The $n r f A$ genes, recovered in lower abundance than nirB in all metagenomes, were significantly more abundant in the Pingtan Sea metagenomes $(12.7 \pm 8.9$ RPKM) than in Xiamen Bay metagenomes (3.1 \pm 3.5 RPKM). Disproportionately large shares of napA, nirB, and $n r f A$ genes were phylogenetically affiliated with Vibrio spp., considering that the relative abundance of Vibrio spp. did not exceed $33 \%$ of the total prokaryotic population according to the $16 \mathrm{~S}$ rRNA-based community composition analyses. At the Pingtan Sea sites where this tendency was more pronounced, $>93.2 \%,>95.8 \%$ and $>56.1 \%$ of the reads mapped onto napA, napB, and nirB, respectively, were phylogenetically affiliated with the genus Vibrio. The gene-coding sequences identified as $n r f A$ were invariably phylogenetically affiliated with Vibrio spp. in all metagenomes, and the relative abundance of Vibrio spp. exhibited significant correlation with that of $\operatorname{nrf} A$ ( $p<0.05$ according to the Spearman's rank correlation).

Compared to the functional genes involved with $\mathrm{NO}_{3}{ }^{-}-\mathrm{to}-\mathrm{NO}_{2}{ }^{-}$reduction and DNRA, the functional genes encoding key enzymes for nitrification and denitrification were, in general, recovered in relatively low abundance (Fig. 3c). The gene abundance of $a m o A$ was below 3.1 RPKM in all metagenomes $(1.8 \pm 0.7$ and 1.9 \pm 1.7 RPKM at the Pingtan Sea and Xiamen Bay sites, respectively), and all recovered $a m o A$ sequences were affiliated with ammonia oxidizing archaea (AOA) of the Candidatus genus Nitrosomarinus. Despite relatively high $\mathrm{NH}_{4}{ }^{+}-\mathrm{N}$ concentrations measured at the Pingtan and Xiamen Bay sites ( $0.23 \pm 0.10$ and $0.31 \pm 0.11 \mathrm{mg} / \mathrm{L}$, respectively), no bacterial $a m o A$ was recovered in any of the metagenomes. The collective relative abundance of $n x r B$, narG, and narZ were 5.1 \pm 2.7 and 9.1 \pm 2.8 RPKM at the Pingtan Sea and Xiamen Bay sites, respectively. No nirS gene, encoding cytochrome $c d_{1}$ nitrite reductase, was found in any metagenome, and the relative abundance of the nirK genes, encoding the copper-dependent nitrite reductase, was below 1.5 RPKM. Notably, the $n r f A$-tonirK and nirB-to-nirK ratios were significantly higher in the Pingtan Sea metagenomes $(80.1 \pm 68.0$ and $352.5 \pm 291.2$, respectively) than in the Xiamen Bay metagenomes (2.6 \pm 2.2 and $34.4 \pm 19.8$, respectively), and the PIN4 site, with by far the highest algal biomass, exhibited the highest nrfA-to-nirK and nirB-to-nirK ratio (163.1 and 532.3, respectively). This selective enrichment of $n r f A$ in the Pingtan Sea metagenomes appear too heavily biased to be solely attributable to the high relative abundance of Vibrio spp. 
$(12.5 \pm 12.5 \%$, versus $5.8 \pm 9.1 \%$ of Xiamen Bay metagenomes). None of the signature genes for nitrogen fixation ( $n i f D H K)$ or anammox ( $h z s$ and $h d h$ ) was recovered at a significant abundance (<1.7 RPKM).

Metagenomic interrogation of phosphorus uptake and metabolism also identified several notable differences between the Pingtan Sea and Xiamen Bay microbiomes (Fig. 3a and Fig. 3d). The ugpABCE genes, encoding ATP-binding cassette ( $A B C$ ) transporters for uptake of glycerol-3-phosphate and glycerophocholine, were found in significantly higher relative abundance in the Pingtan Sea metagenomes than in the Xiamen Bay metagenomes. The phosphonate transporter gene phnD and the high-affinity phosphate binding protein pstS, were both also significantly more abundant in the Pingtan Sea microbiomes (51.7 \pm 15.0 RPKM and $75.5 \pm 21.6$ RPKM, respectively) than in the Xiamen Bay microbiomes (27.4 \pm 5.7 RPKM and 50.9 \pm 11.8 RPKM, respectively). As these phosphorus uptake genes are known to be expressed under $\mathrm{P}_{\mathrm{i}}$-deficient conditions to cope for phosphorus starvation, their abundance in Pingtan Sea metagenomes was consistent with the low concentrations of soluble reactive phosphorous $\left(7.9 \pm 4.3 \times 10^{-3} \mathrm{mg} / \mathrm{L}\right)$ at the Pingtan Sea sites [40-42]. Substantial proportions of

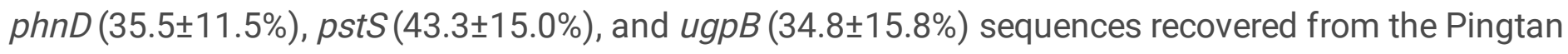
Sea metagenomes were affiliated with Vibrio spp., suggesting that possession of these diverse means of alternative phosphorus uptake may have contributed to the disproportionate proliferation of Vibrio spp. observed in Pingtan Sea.

The genes encoding three distinct forms of alkaline phosphatases, phoA, phoX, and phoD, were found in all metagenomes, and $p h O A$ and $p h o D$, both with RPKM values above 50 , were among the most abundant nitrogen- or phosphorus-related functional genes in the metagenomes (Fig. 3d). The phoA genes were significantly more abundant in the Pingtan metagenomes (68.7 \pm 8.4 RPKM) than in the Xiamen Bay metagenomes (49.5 $\pm 2.6 \mathrm{RPKM} ; p<0.05)$; however, the abundances of $p h o X$ and $p h o D$ were not significantly different between the two regions $(p>0.05)$. In the Pingtan metagenomes, Vibrio-affiliated sequences accounted for the majority of $p h o X(62.3 \pm 13.4 \%)$, while only $13.6 \pm 7.0 \%$ and $0.8 \pm 0.5 \%$ of $p h o A$ and $p h o D$, both at least 3.4-fold more abundant than $p h o X$, were affiliated with Vibrio spp. Therefore, the abundances of alkaline phosphatase genes appear to have little relevance to Vibrio proliferation or Prorocentrum bloom.

\section{Vibrio-dinoflagellate relationship as inferred from the microbial network analysis of the core microbiome}

Microbial network analysis of the core microbiome further substantiated the alleged association between abundance of Vibrio spp. and dinoflagellate bloom (Fig. 4). The relative abundances of two core microbiome taxa, including Pseudoalteromonas and an unidentified genus of the family Cryomorphaceae, showed significant positive correlation with the algal biomass, and the relative abundances of four other core microbiome taxa exhibited significant negative correlation (Spearman's $|r|>0.7, p<0.05 ;$ Fig. 4). The core microbiome taxon affiliated to the genus Vibrio was positively but not significantly correlated with algal biomass $(r=0.26, p=0.53)$; however, its relative abundance had strong significant positive correlation $(r=0.81, p=0.015)$ with the relative abundance of Pseudoalteromonas, and significant negative correlations with those of three core microbiome taxa negatively correlated with algal 
biomass, including Marine Group II of the phylum Euryarchaeota, an unidentified genus of the family Parvibaculaceae, and the IS-44 subgroup of the family Nitrosomonadaceae $(r=-0.71, p=0.047 ; r=-0.71$, $p=0.047 ; r=-0.79, p=0.021$, respectively). Of note, co-abundance of Pseudoalteromonas spp. with eukaryotic algae has been previously observed and mechanistically explained with basis on the capability of the microorganisms belonging to this taxon to prey on eukaryotic algae [43]. Alongside the observation that Vibrio spp. was the single most abundant taxon in the PIN4 microbiome most severely affected by $\mathrm{HAB}$, these co-occurrence patterns surrounding Vibrio in the core microbiome network corroborate the possibility of a causal association of Vibrio spp. with HAB, despite the lack of statistically significant correlation between the relative abundance of the Vibrio and the algal biomass.

\section{Ecological association of Vibrio spp. with dinoflagellate algal bloom}

As these metagenome analyses suggest, association of Vibrio spp. to the Prorocentrum-dominated algal blooms was apparent in the examined segment of coastal East China Sea. Strong significant correlations between the abundance of Vibrio spp. and the environmental metrics for eutrophication (TSI; $r=0.833$, $p=0.011)$ as well as the chlorophyll a concentration $(r=0.762, p=0.028)$ also support that the Vibrio and algal proliferation may be mechanistically correlated (Table S5). These observations are in line with a number of previous studies that have reported occurrences of Vibrio blooms in coastal seas simultaneous with blooms of phytoplanktons, e.g., cyanobacteria, diatoms, and dinoflagellates, or immediately following their demise [44-48]. In a study that monitored microbial population dynamics over a six-year period off the coast of Plymouth, UK, the time point at which a single Vibrio sp. dominated the prokaryotic population, representing $54 \%$ of the entire pool of $16 \mathrm{~S}$ rRNA sequences, coincided with a peak in the population of a diatom species Chaetoceros compressus [44]. Another study performed during raphidophyte blooms in Delaware's inland bays identified significant correlation between the abundances of particle-associated Vibrio spp. and the raphidophyte population [45].

These previous studies have attributed the Vibrio-algae association to protection from zooplankton predation and/or provision of algal exudates or detritus as organic substrates to opportunistic fastgrowing Vibrio spp. [45-47]. Although Vibrio spp. may form biofilms attached to microalgal cells and detritus, physically and chemically protected from grazing, recent culture-independent studies have repeatedly identified particle-associated fractions as minor fractions of Vibrio population in seawater [49]. Thus, supply of labile organics, photosynthetically produced and released by algal counterparts, is deemed more likely as the primary mechanism via which algal blooms accommodate disproportionate proliferation of Vibrio spp. [50]. Further, several Vibrio species have been physiologically characterized as alginolytic, and thus may be able to utilize dead algal biomass or even be algicidal. In this study, core microbiome analysis identified a strong significant positive correlation between Vibrio and Pseudoalteromonas, a taxon widely-known to include algicidal bacteria [51]. This correlation may be interpreted as two groups of specialists sharing a habitat abound with their common substrates, i.e., live or dead algal biomass and/or algae-derived organic materials. It may also be possible that smaller organic compounds produced from Pseudoalteromanas-mediated algal biomass digestion may serve as more labile organic substrates for fast-growing Vibrio spp. [50]. Either hypothesized mechanism would be 
consistent with the co-occurrence of Vibrio proliferation and Prorocentrum-dominant algal bloom observed in this study.

Whether the presumed Vibrio-Prorocentrum association may be a commensal relationship, benefitting only Vibrio spp., or a mutually-beneficial symbiotic relationship, has not been previously discussed. The comparative metagenomic analysis of the functional genes related to nitrogen metabolism suggest possible scenarios how Vibrio proliferation may provide positive feedback to growth of Prorocentrum spp. and other eukaryotic microalgae. The proportion of Vibrio-associated functional genes were, in general, higher at the Pingtan Sea sites than at the Xiamen Bay sites, probably due merely to the higher Vibrio abundance; however, Vibrio's exclusive ownership of DNRA-related functional genes, i.e., napAB and $n r f A$, and the near complete absence of denitrification-related functional genes (nirK and nirS) that are often found in genomes of marine heterotrophic bacteria (e.g., algicidal

Pseudoalteromonas spp.) are not explicable merely with the high Vibrio abundance. The DO concentrations of the bulk seawater at the Pingtan Sea sites, including the PIN4 site with the highest Prorocentrum population and algal biomass, indicated that the bulk seawater was oxic at the time of sampling, which, due to logistical reasons, took place during the daytime. Under oxic conditions, DNRA is not likely to occur, as it is known as a strictly anaerobic process; however considering the high populations of the fast-metabolizing Vibrio and Prorocentrum that may be potent $\mathrm{O}_{2}$ sinks at dark hours, it is plausible that periodic oxic-anoxic shifts may occur in the region, especially at highly eutrophicated locales such as the PIN4 and PIN5 sites [52, 53]. Spatial microaerobic or anoxic niches may also exist, such as in biofilms attached to particle surfaces, microbial aggregates, and intracellular spaces within zooplankton or phytoplankton where Vibrio spp. may be able to colonize [52,54-56]. Rapid decay of algal carcass, and/or upwelling of hypoxic bottom water may also cause temporal anoxia that may not be captured by snapshots of DO measurement $[57,58]$. Further, the redox potentials measured in situ at the Pingtan Sea $(43.9 \pm 2.5 \mathrm{mV}$ ) sites were in fact, substantially lower than the standard redox potentials (at $\mathrm{pH}$ 7.0) of $\mathrm{NO}_{3}{ }^{-}$-to- $\mathrm{NO}_{2}{ }^{-}(420 \mathrm{mV})$ and $\mathrm{NO}_{2}{ }^{-}$-to- $\mathrm{NH}_{4}{ }^{+}$reduction $(440 \mathrm{mV})$, despite the $\mathrm{DO}$ concentrations ranging between $4.73-6.89 \mathrm{mg} \mathrm{L}^{-1}$. Thus, it is highly likely that at least some of the napAB-and $n r f A-$ possessing Vibrio spp. are DNRA-active, producing $\mathrm{NH}_{4}{ }^{+}$from $\mathrm{NO}_{3}{ }^{-}$and possibly supplying Prorocentrum spp. with $\mathrm{NH}_{4}{ }^{+}$, generally known as a more efficient nitrogen source for fast-growing dinoflagellates than $\mathrm{NO}_{3}{ }^{-}[59]$. Although any decisive conclusion cannot be reached solely based on the metagenome analysis, the findings from this study are certainly compelling indications that $\mathrm{NH}_{4}{ }^{+}-$ production via DNRA may be key to the hypothesized symbiotic association between Vibrio spp. and Prorocentrum spp. and warrant further attention to the role that DNRA may play in Prorocentrumdominated HAB.

\section{Conclusions}

Occurrences of severe marine algal blooms are often attributed to nitrogen and/or phosphorus enrichment relieving nutrient limitations to algal growth; however conclusive evidence of the presumed correlation between the nutrient conditions and algal population has remained elusive. In this study, we 
attempted a different avenue of approach, using comparative metagenomics to investigate any association between surface seawater microbiomes and Prorocentrum-dominated algal blooms in East China Sea. The most prominent feature that distinguished the microbiomes of Pingtan Sea with frequent

severe Prorocentrum blooms from that of Xiamen Bay much less frequently affected was enrichment of organisms affiliated with Vibrio spp. and disproportionately biased affiliation of napAB and nrfA to this taxon. The alleged association between DNRA-capable Vibrio spp. and algal bloom in this locale was further substantiated via core microbiome network analysis. The findings suggest a previously unidentified causal association between Vibrio proliferation and dinoflagellate bloom in subtropical marine environment and broach the possibility that DNRA may play a key role in mutually beneficial symbiosis between the two groups of organisms.

\section{Methods}

\section{Sample collection and in situ treatment and characterization}

Sampling was performed at five locations along the coast of Pingtan Island $\left(119^{\circ} 49^{\prime}-119^{\circ} 52^{\prime} \mathrm{E}\right.$, $\left.25^{\circ} 28^{\prime}-25^{\circ} 36^{\prime} \mathrm{N}\right)$ and three coastal locations in the Xiamen Bay $\left(118^{\circ} 0^{\prime}-118^{\circ} 10^{\prime} \mathrm{E}, 24^{\circ} 25^{\prime}-24^{\circ} 36^{\prime} \mathrm{N}\right)$ in the mornings of April 27 and 29, 2018, respectively (Fig. 1a). Bulk seawater samples were collected from the surface layer (0-1 m depth) using hydrophores. The physicochemical properties of the seawater samples, i.e., water temperature, dissolved oxygen concentration, conductivity, salinity, oxidation-reduction potential and $\mathrm{pH}$, were measured on site immediately after sampling, using Professional Plus handheld multiparameter meter (YSI Inc., Yellow Springs, $\mathrm{OH}$ ). Secchi disk transparency (SD) was determined on site according to the standard protocol [60]. Ten liters of each seawater sample was filtered through a phytoplankton net with $20 \mu \mathrm{m}$ mesh size (Xuanmingyu, Wuhan, China) and one liter of the filtrate was passed through a 0.22- $\mu \mathrm{m}$ membrane filter to collect biomass (Merck Millipore, Burlington, MA). The phytoplankton nets and membrane filters were preserved in $2 \%$ formalin solution for transport to the Institute of Fish Resources in Varga, Bulgaria, where the resuspended phytoplankton cells were examined with an Olympus BX43 phase contrast microscope (Tokyo, Japan) [61]. The phytoplankton cells resuspended from the phytoplankton nets were used for exhaustive identification of phytoplankton taxa, and algal cell counting was performed with the membrane filter retentates. Algal biomass was calculated from biovolumes of phytoplankton cells estimated from cell morphology [61]. The remaining phytoplankton net filtrate was transported to the laboratory at Wuhan Institute of Hydrobiology in icefilled coolers for DNA extraction.

Further characterization of the seawater samples was performed in the laboratory. Portions of bulk water samples were filtered through $0.22-\mu \mathrm{m}$ membrane filters (Merck Millipore) for quantification of dissolved nitrogen and phosphorus species. The $\mathrm{NH}_{4}{ }^{+}-\mathrm{N}_{1} \mathrm{NO}_{3}{ }^{-} \mathrm{N}$, and $\mathrm{NO}_{2}{ }^{-} \mathrm{N}$ concentrations were determined colorimetrically as previously described [62]. The dissolved inorganic nitrogen (DIN) concentration was calculated as the sum of the concentrations of these three nitrogen species. The soluble reactive phosphorus (SRP) concentration was determined using the molybdate blue method [63]. Measurements of SRP concentrations were repeated with the filtrates digested for $0.5 \mathrm{~h}$ with $5 \%$ alkaline persulphate 
solution ( $\mathrm{pH}$ 12) for determination of the dissolved total nitrogen and dissolved total phosphorus (DTP) concentrations inclusive of the organic fractions [64]. Unfiltered seawater samples were processed identically for determination of the total nitrogen (TN) and total phosphorus (TP) contents. The chlorophyll a contents ( $\mathrm{Chl} \mathrm{a)} \mathrm{were} \mathrm{determined} \mathrm{using} \mathrm{the} \mathrm{ethanol} \mathrm{extraction} \mathrm{method} \mathrm{[65].} \mathrm{The} \mathrm{trophic} \mathrm{state}$ index (TSI) was calculated from Chl a, SD and TP as previously described [66].

\section{DNA extraction and processing}

In the laboratory, 1-1.5 L of each phytoplankton net-filtered seawater was filtered with a sterile $0.22-\mu \mathrm{m}$ membrane filter (Merck Millipore, Burlington, MA) and the filters were immediately stored at $-80^{\circ} \mathrm{C}$. DNA was extracted from the filter retentate with the CTAB method, and the purity and quantity of the extracted DNA was assessed with the Qubit ${ }^{\circledR} 2.0$ Fluorometer (Thermo Fisher Scientific, Waltham, MA) [67-69]. Each DNA sample was disrupted using a Covaris S2 sonicator (Woburn, MA). Sequencing libraries were generated using the TruSeq Nano DNA HT sample preparation kit (Illumina, San Diego, CA). The shotgun metagenome libraries were sequenced with an Illumina NovaSeq-PE150 platform, generating 150-bp paired-end reads with a targeted throughput of $12 \mathrm{~Gb}$ per sample.

Quantitative PCR (qPCR) assay targeting the 16S rRNA gene was performed with the extracted DNA for estimation of prokaryotic population in the seawater samples. The V3-V4 region of the 16S rRNA gene was targeted with the $319 f$ (5'-ACTCCTACGGGAGGCAGCAG-3') - 806r (5'-GGACTACHVGGGTWTCTAAT-3') degenerate primer pair [70]. All qPCR reactions were performed with a CFX96 Real-time PCR System (BioRad, Hercules, CA, USA) using SYBR-Green detection chemistry (Jizhenbio, Shanghai, China). The calibration curve was constructed with a serial dilution series of $16 \mathrm{~S}$ rRNA gene PCR fragments amplified from DNA isolated from a seawater sample and inserted in PCR2. $1^{\circledR}$ vectors.

\section{Microbial community analysis and metagenomic analysis of nitrogen and phosphorus metabolism}

Low-quality reads were removed from the raw sequence data using Trimmomatic v0.36 with the parameters set as follows: LEADING: 3, TRAILING: 3, SLIDINGWINDOW: 4:15, and MINLEN:70 [71]. The quality-trimmed reads were screened for putative 16S rRNA gene fragments, using the hmmsearch-based Meta-RNA 3 software, with the parameters molecule type and e-value set to "ssu" and "1E-10", respectively [72]. These reads were reconstructed to full-length 16S rRNA gene sequences using EMERGE through 100 iterations with Silva SSU database release 132 as reference [73]. A QIIME-compatible OTU table was constructed with these full-length 16S rRNA gene sequences and the relative abundances of the OTUs were computed using an in-house python script, which converted the normalized coverage of each EMIRGE-synthesized 16S rRNA gene to an OTU count. The OTUs were assigned taxonomic classification using RDP classifier v2.10.2 with Silva SSU database 132 as the reference dataset and the parameter min_confidence set to 0.8 . The OTUs assigned to chloroplasts were removed for the downstream analysis [74].

For metagenomic analysis of the functional genes relevant to nitrogen- and phosphorous-metabolism, the quality-trimmed sequence reads were assembled de novo using metaSPAdes v3.14.0 with the 
parameters set to default values, and gene-coding sequences in the contigs were predicted using Prodigal v2.6.3 $[75,76]$. The predicted coding sequences were assigned functional and taxonomic annotations using DIAMOND v0.9.31.132 with NCBI's non-redundant protein database (accessed on 1/2/2020) and the Uniref90 database (accessed on 4/9/2020) as reference and the parameters set to default values [77]. For each gene-coding sequence, only the hit that returned the highest score was taken for downstream analyses. GhostKOALA (https://www.kegg.jp/ghostkoala/) assigned KEGG Orthology (KO) numbers to the gene-coding sequences [78]. For annotation of carbohydrate-active enzymes (CAZymes), the predicted gene-coding sequences were searched against dbCAN HMMdb release 9.0 using the hmmscan command in HMMER v3.1b2 [79]. Assembled contigs from the individual samples were pooled together, and for each sample, quality-trimmed raw sequence reads were mapped onto these contigs using the BWA mem v0.7.17 software (default parameters). Read counts were performed using HTSeq v0.12.4 [80, 81]. The raw counts of the coding sequences were normalized with the nucleotide length (in kilobases) and the total read count of the sample analyzed (in million reads), yielding gene coverage values in RPKM (reads per kilobase per million mapped reads).

\section{Statistical analysis}

Statistical analyses in this study were performed using nonparametric methods, due to the small sample size ( $n \leq 8)$. All statistical analyses were performed using R v4.0.2 [82]. Pairwise comparisons of the environmental parameters between sampling sites were statistically evaluated with Student's $t$-test using wilcox.test function implemented in the "stats" package. Spearman's rank correlation tests were performed to evaluate statistical significance of pairwise correlations between the environmental parameters. Mantel tests evaluated pairwise correlations among physicochemical parameter matrices, the algal biomass data, the microbial community profiles, the KEGG Orthology (KO) number-based functional gene abundance profiles, and the CAZymes profiles. The dissimilarity matrices for these datasets were constructed using either Bray-Curtis dissimilatory metrics (vegdist function in "vegan" package) or Euclidean distance metrics (dist function in "stats" package), and these dissimilatory matrices were used as the inputs for the Mantel tests performed using the mante/ function implemented in "vegan" package, with the 'correlation method' and 'permutation' options set to spearman and 9999, respectively.

The non-metric multidimensional scaling (NMDS) analyses of microbial communities and functional gene compositions were performed based on the Bray-Curtis dissimilarity matrices constructed using metaMDS function embedded in "vegan" package. The co-occurrence networks were constructed based on the pairwise Spearman's correlation analyses performed with the relative abundances of the selected OTUs, using cor.test function in "stats" package. Co-occurrence networks visualizing the connections between the OTUs exhibiting significant correlations $(p<0.05)$ were constructed using Cytoscape v3.7.2 [83].

\section{Declarations}




\section{Ethics approval and consent to participate}

Not applicable

\section{Consent for publication}

Not applicable

\section{Availability of data and materials}

The raw sequence data generated in the current study have been deposited in NCBI SRA database under accession number of PRJNA739281.

\section{Competing interests}

The authors declare that they have no known competing financial interests or personal relationships that could have appeared to influence the work reported in this paper.

\section{Funding}

This work was financially supported by grants from the National Key Research and Development Program of China (2016YFE0202100) and Natural Science Foundation of China (41611540341, 41877381), and internal funding from the State Key Laboratory of Freshwater Ecology and Biotechnology (2019FBZ01).

\section{Authors' contributions}

DDK and LW contributed equally for the preparation of the manuscript. XC, YZ, CS, and SY designed the experiments. LW, XC, YZ, and CS collected seawater samples and performed on-site experiments. LW, DK, and DG performed laboratory experiments, including DNA extraction and library preparation. DDK and SY performed statistical and metagenomic analyses. DDK, LW, XC, YZ, CS, and SY drafted the manuscript.

\section{Acknowledgements}

The authors would like to thank Prof. Bongkeun Song (Virginia Institute of Marine Science, USA) for kindly reviewing the manuscript and providing invaluable suggestions.

\section{References}

1. Anderson DM, Cembella AD, Hallegraeff GM. Progress in understanding harmful algal blooms: paradigm shifts and new technologies for research, monitoring, and management. Annu Rev Mar Sci. 2012;4:143-76.

2. Tang D, Di B, Wei G, Ni I-H, Wang S. Spatial, seasonal and species variations of harmful algal blooms in the South Yellow Sea and East China Sea. Hydrobiologia. 2006;568:245-53. 
3. Heil CA, Glibert PM, Fan C. Prorocentrum minimum (Pavillard) Schiller: A review of a harmful algal bloom species of growing worldwide importance. Harmful Algae. 2005;4:449-70.

4. Lu D, Goebel J, Qi Y, Zou J, Han X, Gao Y, Li Y. Morphological and genetic study of Prorocentrum donghaiense Lu from the East China Sea, and comparison with some related Prorocentrum species. Harmful Algae. 2005;4:493-505.

5. Shin HH, Li Z, Mertens KN, Seo MH, Gu H, Lim WA, Yoon YH, Soh HY, Matsuoka K. Prorocentrum shikokuense Hada and $P$. donghaiense Lu are junior synonyms of P. obtusidens Schiller, but not of $P$. dentatum Stein (Prorocentrales, Dinophyceae). Harmful Algae 2019;89:101686.

6. Ben-Gharbia H, Yahia OK-D, Amzil Z, Chomerat N, Abadie E, Masseret E, Sibat M, Triki HZ, Nouri H, Laabir M. Toxicity and growth assessments of three thermophoilic benthic dinoflagellates (Ostreopsis cf. ovata, Prorocentrum lima and Coolia monotis) developing in the Southern Mediterranean Basin. Toxins 2016;8:297.

7. Nascimento SM, Mendes MCQ, Menezes M, Rodríguez F, Alves-de-Souza C, Branco S, Riobó P, Franco $\mathrm{J}$, Nunes JMC, Huk M, et al. Morphology and phylogeny of Prorocentrum caipirignum sp. nov. (Dinophyceae), a new tropical toxic benthic dinoflagellate. Harmful Algae. 2017;70:73-89.

8. Gallegos CL, Bergstrom PW. Effects of a Prorocentrum minimum bloom on light availability for and potential impacts on submersed aquatic vegetation in upper Chesapeake Bay. Harmful Algae. 2005;4:553-74.

9. Azanza RV, Fukuyo Y, Yap LG, Takayama H. Prorocentrum minimum bloom and its possible link to a massive fish kill in Bolinao, Pangasinan, Northern Philippines. Harmful Algae. 2005;4:519-24.

10. Yu R-C, Lü S-H, Liang Y-B. Harmful algal blooms in the coastal waters of China. In: Glibert PM, Berdalet E, Burford MA, Pitcher GC, Zhou M, editors. Global Ecology and Oceanography of Harmful Algal Blooms. Cham: Springer Nature; 2018. pp. 309-16.

11. Li Y, Lü S, Jiang T, Xiao Y, You S. Environmental factors and seasonal dynamics of Prorocentrum populations in Nanji Islands National Nature Reserve, East China Sea. Harmful Algae. 2011;10:42632.

12. Tang D, Di B, Wei G, Ni IH, Oh IS, Wang S. Spatial, seasonal and species variations of harmful algal blooms in the South Yellow Sea and East China Sea. Hydrobiologia. 2006;568:245-53.

13. Varkitzi I, Pagou K, Granéli E, Hatzianestis I, Pyrgaki C, Pavlidou A, Montesanto B, Economou-Amilli A. Unbalanced $N: P$ ratios and nutrient stress controlling growth and toxin production of the harmful dinoflagellate Prorocentrum lima (Ehrenberg) Dodge. Harmful Algae. 2010;9:304-11.

14. Glibert PM, Mayorga E, Seitzinger S. Prorocentrum minimum tracks anthropogenic nitrogen and phosphorus inputs on a global basis: application of spatially explicit nutrient export models. Harmful Algae. 2008;8:33-8.

15. Li J, Glibert PM, Zhou M. Temporal and spatial variability in nitrogen uptake kinetics during harmful dinoflagellate blooms in the East China Sea. Harmful Algae. 2010;9:531-9.

16. Zhou Y, Zhang Y, Li F, Tan L, Wang J. Nutrients structure changes impact the competition and succession between diatom and dinoflagellate in the East China Sea. Sci Tot Environ. 
2017;574:499-508.

17. Kuypers MMM, Marchant HK, Kartal B. The microbial nitrogen-cycling network. Nat Rev Microbiol. 2018;16:263-76.

18. Beman MJ, Popp BN, Alford SE. Quantification of ammonia oxidation rates and ammonia-oxidizing archaea and bacteria at high resolution in the Gulf of California and eastern tropical North Pacific Ocean. Limnol Oceanogr. 2012;57:711-26.

19. Wankel SD, Kendall C, Pennington JT, Chavez FP, Paytan A. Nitrification in the euphotic zone as evidenced by nitrate dual isotopic composition: observations from Monterey Bay, California. Glob Biogeochem Cycles. 2007;21:GB2009.

20. Dore JE, Karl DM. Nitrification in the euphotic zone as a source for nitrite, nitrate, and nitrous oxide at Station ALOHA. Limnol Oceanogr. 1996;41:1619-28.

21. Mahmud M, Ejeian F, Azadi S, Myers M, Pejcic B, Abbasi R, Razmjou A, Asadnia M. Recent progress in sensing nitrate, nitrite, phosphate, and ammonium in aquatic environment. Chemosphere 2020;127492.

22. Patey MD, Rijkenberg MJ, Statham PJ, Stinchcombe MC, Achterberg EP, Mowlem M. Determination of nitrate and phosphate in seawater at nanomolar concentrations. Trends Anal Chem. 2008;27:16982.

23. Turner EL, Paudel B, Montagna PA. Baseline nutrient dynamics in shallow well mixed coastal lagoon with seasonal harmful algal blooms and hypoxia formation. Mar Pollut Bull. 2015;96:456-62.

24. Conley DJ, Carstensen J, Aigars J, Axe P, Bonsdorff E, Eremina T, Haahti B-M, Humborg C, Jonsson P, Kotta J, et al. Hypoxia is increasing in the coastal zone of the Baltic Sea. Environ Sci Technol. 2011;45:6777-83.

25. Fan C, Glibert PM, Burkholder JM. Characterization of the affinity for nitrogen, uptake kinetics, and environmental relationships for Prorocentrum minimum in natural blooms and laboratory cultures. Harmful Algae. 2003;2:283-99.

26. Sebastian M, Ammerman JW. The alkaline phosphatase PhoX is more widely distributed in marine bacteria than the classical PhoA. ISME J. 2009;3:563-72.

27. Luo H, Benner R, Long RA, Hu J. Subcellular localization of marine bacterial alkaline phosphatases. Proc. Natl. Acad. Sci. 2009;106:21219.

28. Luo H, Moran MA. Assembly-free metagenomic analysis reveals new metabolic capabilities in surface ocean bacterioplankton. Environ Microbiol Rep. 2013;5:686-96.

29. Chin JP, Quinn JP, McGrath JW. Phosphate insensitive aminophosphonate mineralisation within oceanic nutrient cycles. ISME J. 2018;12:973-80.

30. Suzumura M, Hashihama F, Yamada N, Kinouchi S. Dissolved phosphorus pools and alkaline phosphatase activity in the euphotic zone of the Western North Pacific Ocean. Front. Microbiol. 2012; 3.99 . 
31. Thomson B, Wenley J, Currie K, Hepburn C, Herndl GJ, Baltar F. Resolving the paradox: continuous cell-free alkaline phosphatase activity despite high phosphate concentrations. Mar Chem. 2019;214:103671.

32. Hoppe H-G. Phosphatase activity in the sea. Hydrobiologia. 2003;493:187-200.

33. Ou L, Qin X, Shi X, Feng Q, Zhang S, Lu S, Qi Y. Alkaline phosphatase activities and regulation in three harmful Prorocentrum species from the coastal waters of the East China Sea. Microb Ecol. 2020;79:459-71.

34. Labry C, Delmas D, Herbland A. Phytoplankton and bacterial alkaline phosphatase activities in relation to phosphate and DOP availability within the Gironde plume waters (Bay of Biscay). J Exp Mar Biol Ecol. 2005;318:213-25.

35. Mo Y, Ou L, Lin L, Huang B. Temporal and spatial variations of alkaline phosphatase activity related to phosphorus status of phytoplankton in the East China Sea. Sci Tot Environ. 2020;731:139192.

36. Zhuo X. Research on the basic characteristics of red tides along the coast of Fuzhou in the past ten years. Marine Forecast. 2018;35:34-40. (in Chinese).

37. Luria CM, Amaral-Zettler LA, Ducklow HW, Rich JJ. Seasonal succession of free-living bacterial communities in coastal waters of the Western Antarctic Peninsula. Front Microbiol. 2016;7:1731.

38. Bindels LB, Delzenne NM, Cani PD, Walter J. Towards a more comprehensive concept for prebiotics. Nat Rev Gastroenterol Hepatol. 2015;12:303.

39. Heo H, Kwon M, Song B, Yoon S. Involvement of $\mathrm{NO}_{3}{ }^{-}$in ecophysiological regulation of dissimilatory nitrate/nitrite reduction to ammonium (DNRA) is implied by physiological characterization of soil DNRA bacteria isolated via a colorimetric screening method. Appl Environ Microbiol. 2020;86:e01054-01020.

40. Yang $\mathrm{K}$, Wang $\mathrm{M}$, Metcalf WW. Uptake of glycerol-2-phosphate via the ugp-encoded transporter in Escherichia coli K-12. J Bacteriol Res. 2009;191:4667-70.

41. llikchyan IN, McKay RML, Zehr JP, Dyhrman ST, Bullerjahn GS. Detection and expression of the phosphonate transporter gene $p h n D$ in marine and freshwater picocyanobacteria. Environ Microbiol. 2009;11:1314-24.

42. Scanlan DJ, Silman NJ, Donald KM, Wilson WH, Carr NG, Joint I, Mann NH. An immunological approach to detect phosphate stress in populations and single cells of photosynthetic picoplankton. Appl Environ Microbiol. 1997;63:2411-20.

43. Skovhus TL, Ramsing NB, Holmström C, Kjelleberg S, Dahllöf I. Real-time quantitative PCR for assessment of abundance of Pseudoalteromonas species in marine samples. Appl Environ Microbiol. 2004;70:2373-82.

44. Gilbert JA, Steele JA, Caporaso JG, Steinbrück L, Reeder J, Temperton B, Huse S, McHardy AC, Knight $R$, Joint I, et al. Defining seasonal marine microbial community dynamics. ISME J. 2012;6:298-308.

45. Main CR, Salvitti LR, Whereat EB, Coyne KJ. Community-level and species-specific associations between phytoplankton and particle-associated Vibrio species in Delaware's Inland Bays. Appl 
Environ Microbiol. 2015;81:5703-13.

46. Asplund ME, Rehnstam-Holm A-S, Atnur V, Raghunath P, Saravanan V, Härnström K, Collin B, Karunasagar I, Godhe A. Water column dynamics of Vibrio in relation to phytoplankton community composition and environmental conditions in a tropical coastal area. Environ Microbiol. 2011;13:2738-51.

47. Takemura A, Chien D, Polz M. Associations and dynamics of Vibrionaceae in the environment, from the genus to the population level. Front. Microbiol. 2014;5.

48. Eiler A, Johansson M, Bertilsson S. Environmental influences on Vibrio populations in northern temperate and boreal coastal waters (Baltic and Skagerrak Seas). Appl Environ Microbiol. 2006;72:6004-11.

49. Liang J, Liu J, Wang X, Lin H, Liu J, Zhou S, Sun H, Zhang X-H. Spatiotemporal dynamics of freeliving and particle-associated Vibrio communities in the northern Chinese marginal seas. Appl. Environ. Microbiol. 2019;85.

50. Thickman JD, Gobler CJ. The ability of algal organic matter and surface runoff to promote the abundance of pathogenic and non-pathogenic strains of Vibrio parahaemolyticus in Long Island Sound, USA. PLoS One. 2017;12:e0185994.

51. Lee S-O, Kato J, Takiguchi N, Kuroda A, Ikeda T, Mitsutani A, Ohtake H. Involvement of an extracellular protease in algicidal activity of the marine bacterium Pseudoalteromonas sp. strain A28. Appl Environ Microbiol. 2000;66:4334-9.

52. Broman E, Zilius M, Samuiloviene A, Vybernaite-Lubiene I, Politi T, Klawonn I, Voss M, Nascimento FJA, Bonaglia S. Active DNRA and denitrification in oxic hypereutrophic waters. Water Res. 2021;194:116954.

53. Hitchcock GL, Kirkpatrick G, Lane PV, Langdon C. Comparative diel oxygen cycles preceding and during a Karenia bloom in Sarasota Bay, Florida, USA. Harmful algae. 2014;38:95-100.

54. Espinoza-Vergara G, Hoque MM, McDougald D, Noorian P. The impact of protozoan predation on the pathogenicity of Vibrio cholerae. Front Microbiol. 2020;11:17.

55. Bianchi D, Weber TS, Kiko R, Deutsch C. Global niche of marine anaerobic metabolisms expanded by particle microenvironments. Nat Geosci. 2018;11:263-8.

56. van der Henst C, Scrignari T, Maclachlan C, Blokesch M. An intracellular replication niche for Vibrio cholerae in the amoeba Acanthamoeba castellanii. ISME J. 2016;10:897-910.

57. Pitcher GC, Probyn TA, du Randt A, Lucas AJ, Bernard S, Evers-King H, Lamont T, Hutchings L. Dynamics of oxygen depletion in the nearshore of a coastal embayment of the southern Benguela upwelling system. J Geophys Res Oceans. 2014;119:2183-200.

58. Lee JHW, Hodgkiss IJ, Wong K, Lam I. Real time observations of coastal algal blooms by an early warning system. Estuar Coast Shelf Sci. 2005;65:172-90.

59. Ou L-j, Huang K-X, Li J-J, Jing W-Y, Dong H-P. Transcriptomic responses of harmful dinoflagellate Prorocentrum donghaiense to nitrogen and light. Mar Pollut Bull. 2019;149:110617. 
60. Tyler JE. The secchi disc. Limnol Oceanogr. 1968;13:1-6.

61. Olenina I. Biovolumes and size-classes of phytoplankton in the Baltic Sea. 2006.

62. Greenberg AE, Clesceri LS, Eaton AD. Standard methods for the examination of water and wastewater. 22nd ed. Washington, DC; American Public Health Association; 2012.

63. Murphy J, Riley JP. A modified single solution method for the determination of phosphate in natural waters. Anal Chim Acta. 1962;27:31-6.

64. Langner CL, Hendrix PF. Evaluation of a persulfate digestion method for particulate nitrogen and phosphorus. Water Res. 1982;16:1451-4.

65. Nusch E. Comparison of different methods for chlorophyll and phaeopigment determination. Arch Hydrobiol Beih Ergebn Limnol. 1980;14:14-36.

66. Carlson RE. A trophic state index for lakes. Limnol Oceanogr. 1977;22:361-9.

67. Griffith GW, Ozkose E, Theodorou MK, Davies DR. Diversity of anaerobic fungal populations in cattle revealed by selective enrichment culture using different carbon sources. Fungal Ecol. 2009;2:87-97.

68. Raimundo J, Reis CMG, Ribeiro MM. Rapid, simple and potentially universal method for DNA extraction from Opuntia spp. fresh cladode tissues suitable for PCR amplification. Mol Biol Rep. 2018;45:1405-12.

69. Trojánek Z, Kovařík A, Španová A, Marošiová K, Horák D, Rittich B. Application of magnetic polymethacrylate-based microspheres for the isolation of DNA from raw vegetables and processed foods of plant origin. J Food Process Preserv. 2018;42:e13384.

70. Fadrosh DW, Ma B, Gajer P, Sengamalay N, Ott S, Brotman RM, Ravel J. An improved dual-indexing approach for multiplexed 16S rRNA gene sequencing on the Illumina MiSeq platform. Microbiome. 2014;2:6.

71. Bolger AM, Lohse M, Usadel B. Trimmomatic: a flexible trimmer for Illumina sequence data. Bioinformatics. 2014;30:2114-20.

72. Huang Y, Gilna P, Li W. Identification of ribosomal RNA genes in metagenomic fragments. Bioinformatics. 2009;25:1338-40.

73. Miller CS, Baker BJ, Thomas BC, Singer SW, Banfield JF. EMIRGE: reconstruction of full-length ribosomal genes from microbial community short read sequencing data. Genome Biol. 2011;12:114.

74. Caporaso JG, Kuczynski J, Stombaugh J, Bittinger K, Bushman FD, Costello EK, Fierer N, Peña AG, Goodrich JK, Gordon JI. QIIME allows analysis of high-throughput community sequencing data. Nat Methods. 2010;7:335-6.

75. Nurk S, Meleshko D, Korobeynikov A, Pevzner PA. metaSPAdes: a new versatile metagenomic assembler. Genome Res. 2017;27:824-34.

76. Hyatt D, Chen G-L, LoCascio PF, Land ML, Larimer FW, Hauser LJ. Prodigal: prokaryotic gene recognition and translation initiation site identification. BMC Bioinformatics. 2010;11:119. 
77. Buchfink B, Xie C, Huson DH. Fast and sensitive protein alignment using DIAMOND. Nat Methods. 2015;12:59-60.

78. Kanehisa M, Sato Y, Morishima K. BlastKOALA and GhostKOALA: KEGG tools for functional characterization of genome and metagenome sequences. J Mol Biol. 2016;428:726-31.

79. Huang L, Zhang H, Wu P, Entwistle S, Li X, Yohe T, Yi H, Yang Z, Yin Y. dbCAN-seq: a database of carbohydrate-active enzyme (CAZyme) sequence and annotation. Nucleic Acids Res. 2017;46:D51621.

80. Li H. Aligning sequence reads, clone sequences and assembly contigs with BWA-MEM. arXiv 2013;1303.3997.

81. Anders S, Pyl PT, Huber W. HTSeq-a Python framework to work with high-throughput sequencing data. Bioinformatics. 2015;31:166-9.

82. Team RC. R: A language and environment for statistical computing. 2013.

83. Su G, Morris JH, Demchak B, Bader GD. Biological network exploration with Cytoscape 3. Curr. Protoc. Bioinform. 2014;47:8.13.1-8.13.24..

\section{Figures}

a

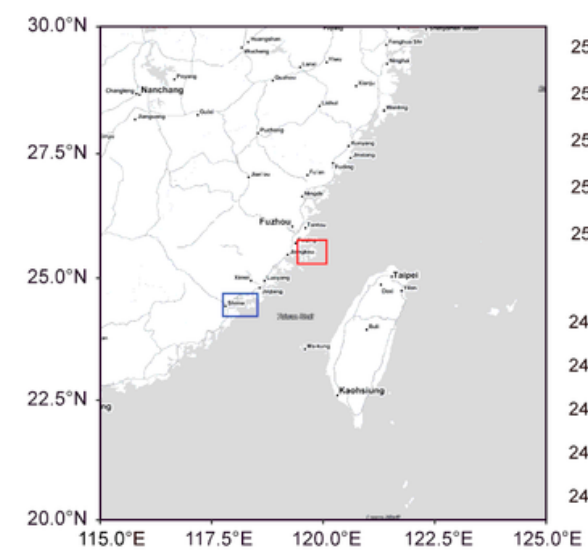

b

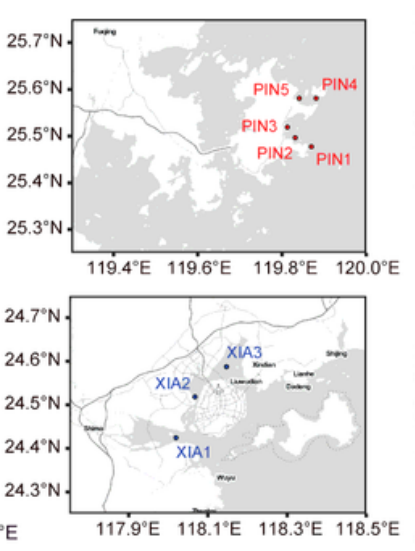

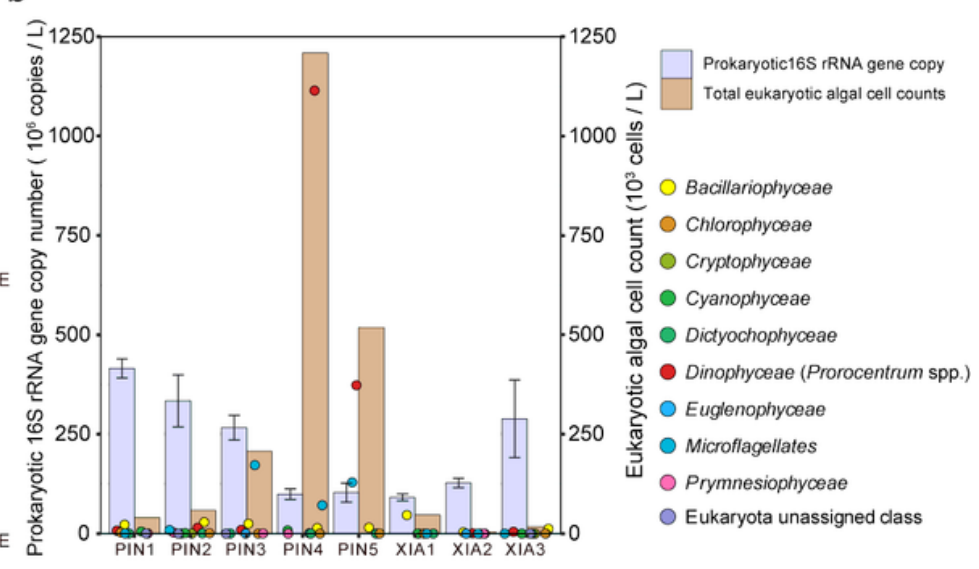

C
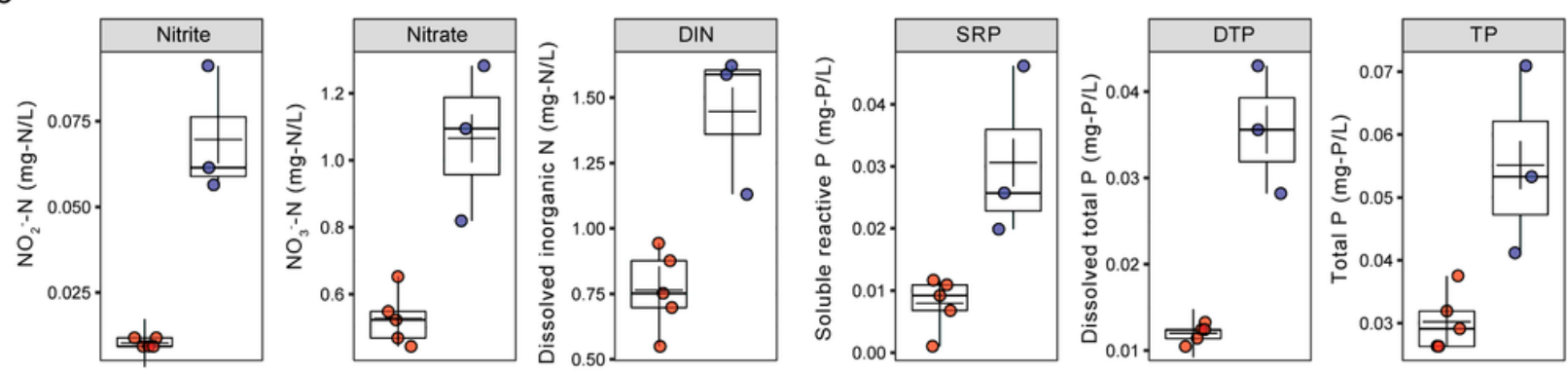

○ Pingtan Sea

- Xiamen Bay

Figure 1

Characterization of the sampling sites along the coastline of Pingtan Island (PIN1-5) and in Xiamen Bay (XIA1-3). (a) Geographical locations of the sampling sites in Pingtan Sea (PIN1-5) and Xiamen Bay (XIA13). (b) Populations of eukaryotic algae determined via direct microscopic counting of morphologically 
classified algal cells and 16S rRNA genes copy numbers as estimates of prokaryotic populations, determined with qPCR assays comprehensively targeting bacterial and archaeal 16S rRNA genes. (c) Nitrogen and phosphorus contents of the surface seawater collected from the sampling sites. Each dot represents a sampling site.

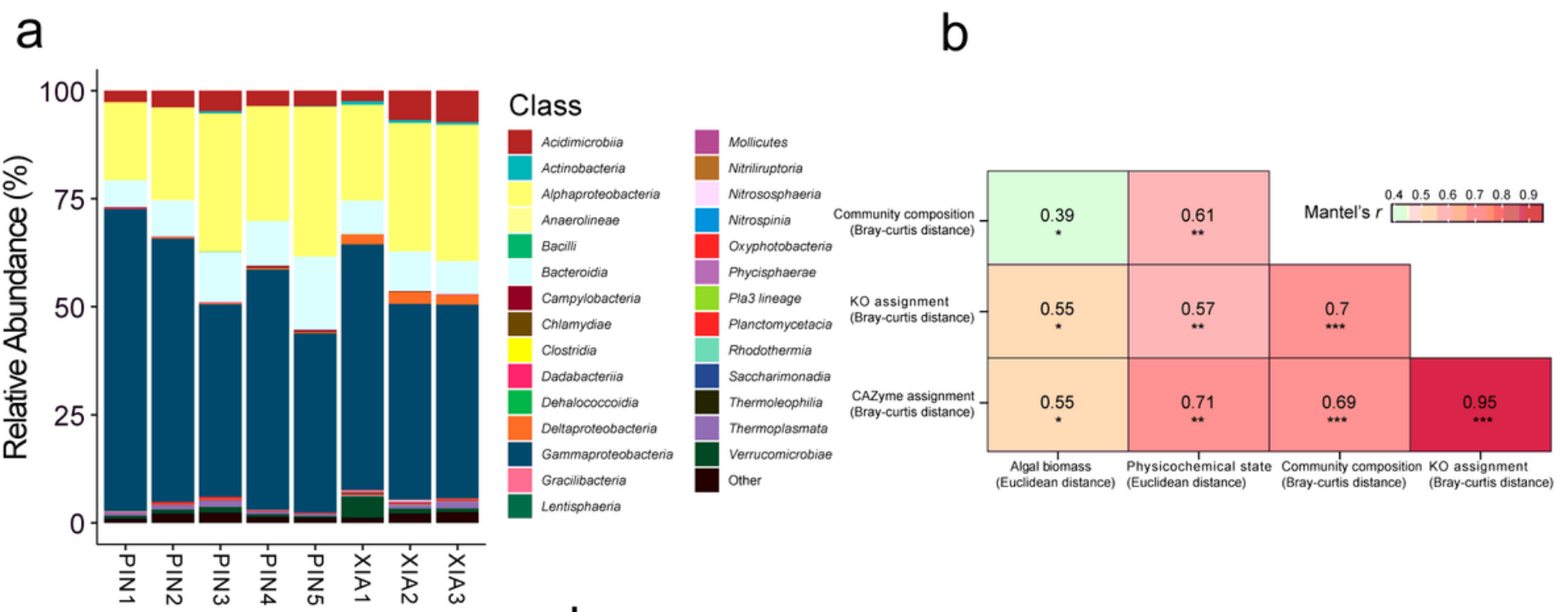

C Microbial communities

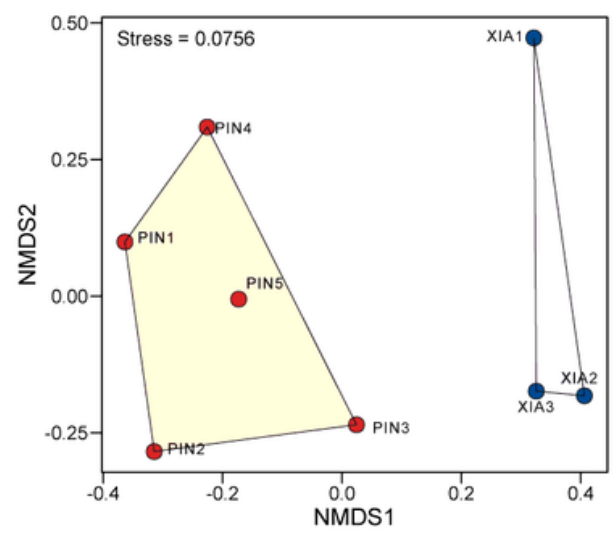

d Functional genes (KO)

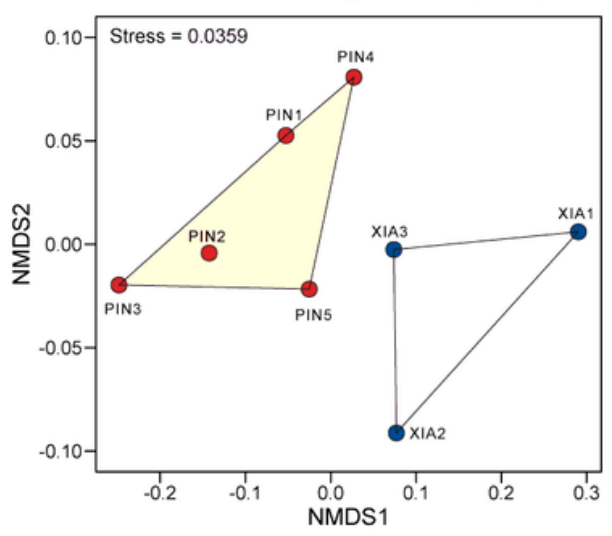

e Functional genes (CAZymes)

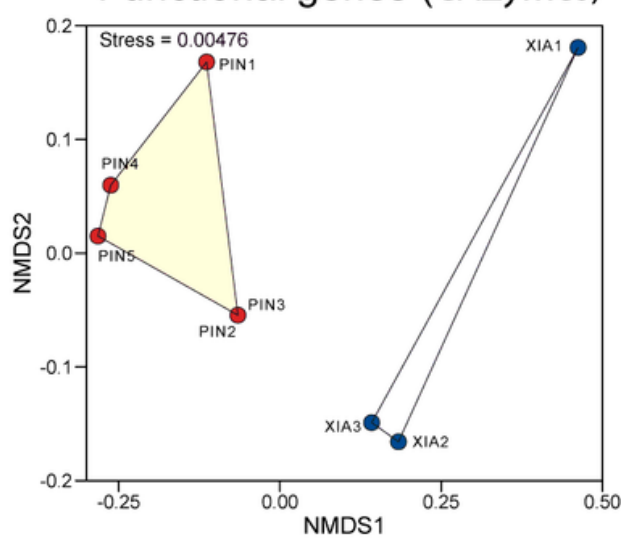

Figure 2

Comparative analyses of the microbial community compositions of the seawater samples collected from Pingtan Sea and Xiamen Bay. (a) Microbial community compositions of the Pingtan Sea (PIN1-5) and Xiamen Bay (XIA1-3) surface water samples according to class-level taxonomic classification. (b) Pairwise correlations among the taxonomic and functional (KO and CAZyme assignments) compositions, physicochemical state, and algal biomass, as evaluated with Mantel tests. The numbers in the boxes are Mantel's $r$ values indicative of the strength of the correlations, and the asterisk marks denote the significance level of the pairwise correlations ( $*$ : $p<0.05, * *: p<0.01, * \star *: p<0.001)$. The NMDS plots constructed with the Bray-Curtis dissimilarity matrices computed from (c) the 16S rRNA-based community compositions and (d) the KO number-based and (e) CAZymes-based functional compositions. 

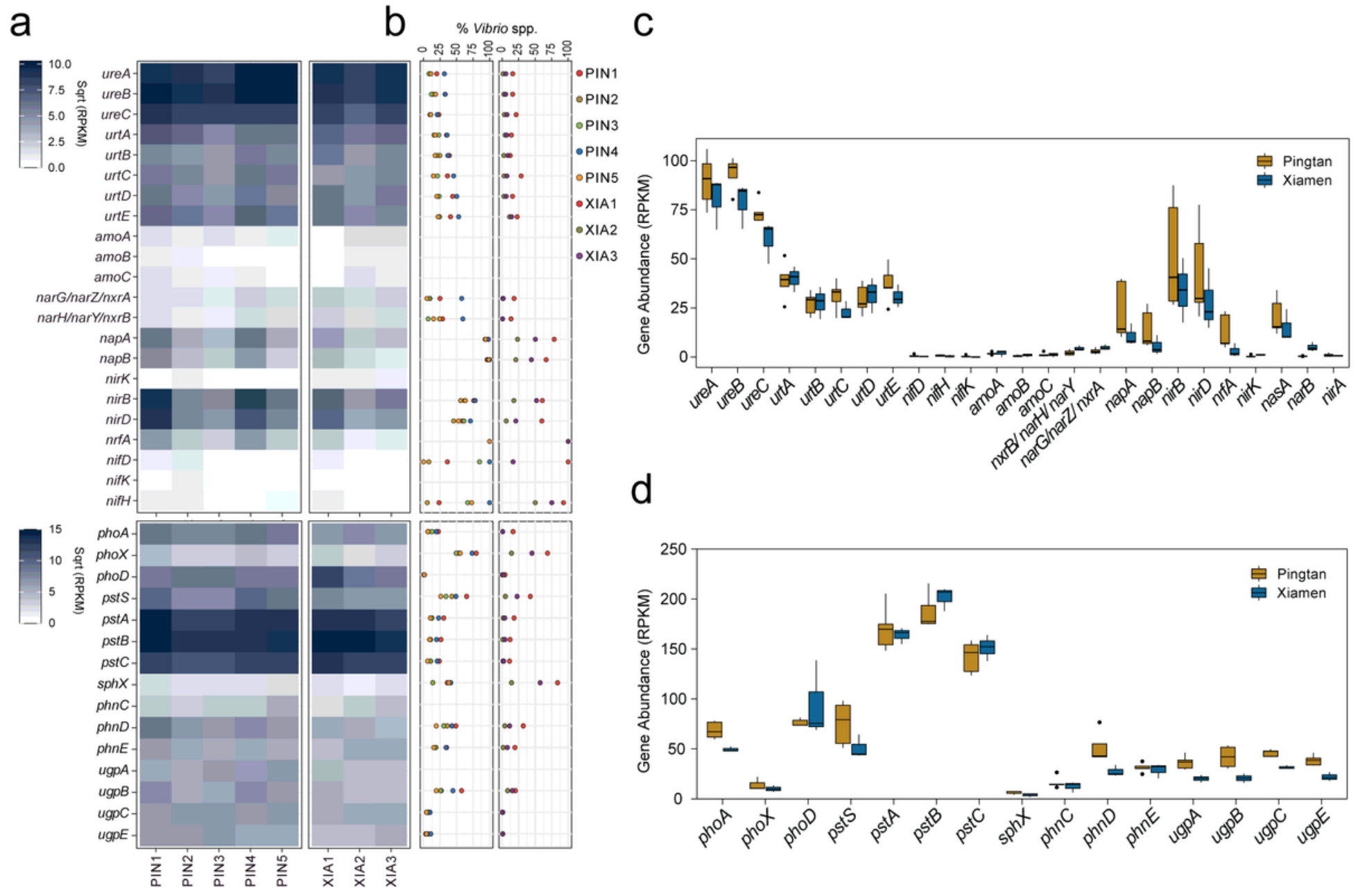

Figure 3

Compilation of the nitrogen- or phosphorus-related functional genes recovered from the metagenomes of the Pingtan Sea and Xiamen Bay microbiomes. (a) The relative abundances of the nitrogen- and phosphorus-related functional genes are presented along with the shares of these functional genes taxonomically assigned to Vibrio spp. (b-c) Quantitative comparisons of (b) nitrogen- and (c) phosphorusrelated genes in the Pingtan Sea and Xiamen Bay microbiomes. 

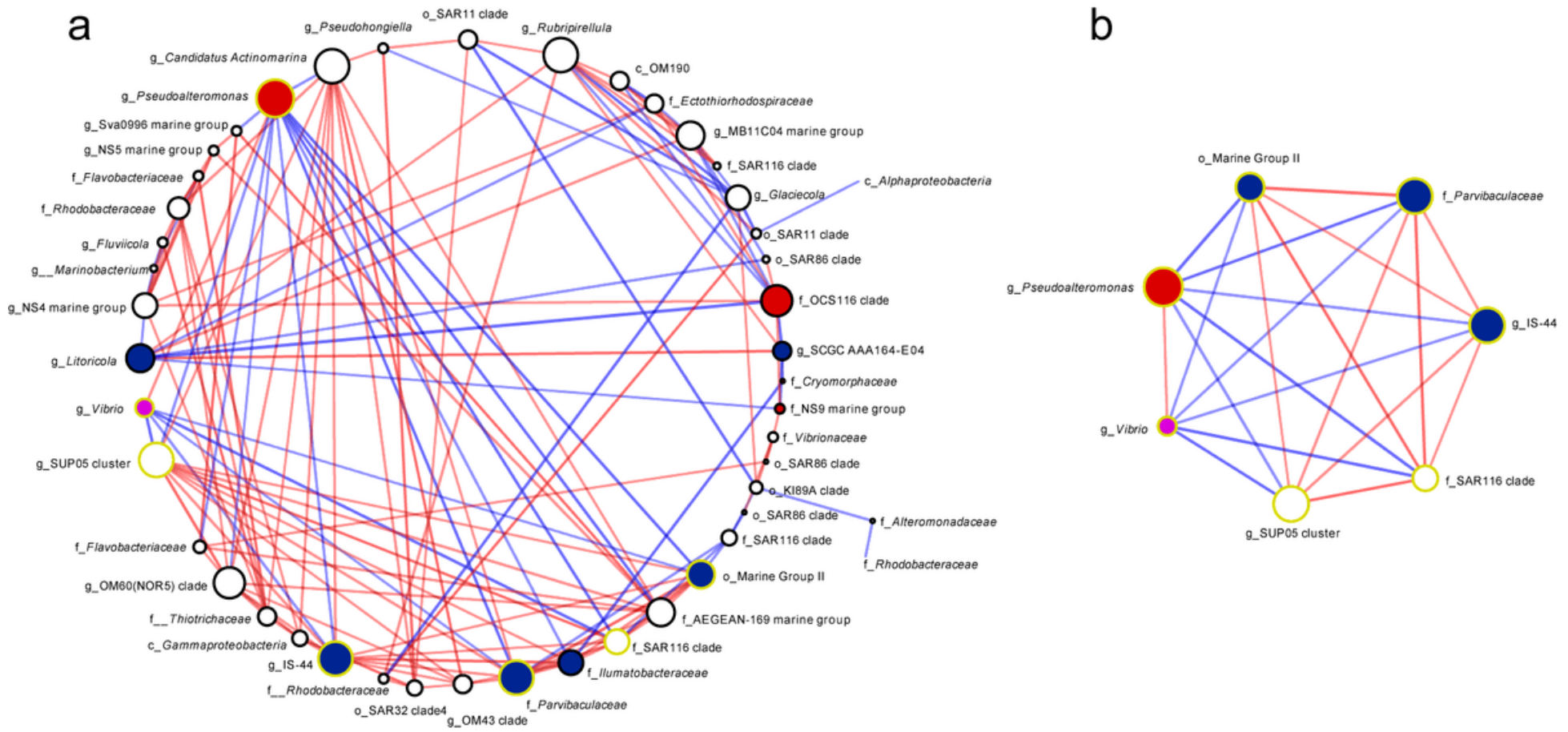

Figure 4

Co-occurrence network analysis of the core microbiome. (a) Co-occurrence network based on the pairwise Spearman's rank correlation analyses performed with the relative abundance data of the 47 core microbiome taxa. Only statistically significant $(p<0.05)$ correlations are visualized with red $(p o s i t i v e)$ or blue (negative) edges, and the thickness of the edges are proportional to the magnitudes of the $r$ values. The size of a node is proportional to the number of edges via which it is connected to other nodes. The color of the nodes indicates taxa which had significantly positive (red) or negative (blue) correlation with algal biomass.s(b) An abridged co-occurrence network constructed with the subset of the core microbiome taxa found to have relative abundances significantly correlated with that of the Vibrio genus (denoted with yellow boundary in (a)).

\section{Supplementary Files}

This is a list of supplementary files associated with this preprint. Click to download.

- Additionalfile1.docx

- TableS1.xlsx

- TableS2.xIsx

- TableS3.xlsx

- TableS4.xlsx 